\title{
Stiffened yeast telomerase RNA supports RNP function in vitro and in vivo
}

\author{
KEVIN J. LEBO and DAVID C. ZAPPULLA ${ }^{1}$
}

Department of Biology, Johns Hopkins University, Baltimore, Maryland 21218, USA

\begin{abstract}
The 1157-nt Saccharomyces cerevisiae telomerase RNA, TLC1, in addition to providing a 16-nt template region for reverse transcription, has been proposed to act as a scaffold for protein subunits. Although accessory subunits of the telomerase ribonucleoprotein (RNP) complex function even when their binding sites are relocated on the yeast telomerase RNA, the physical nature of the RNA scaffold has not been directly analyzed. Here we explore the structure-function organization of the yeast telomerase RNP by extensively stiffening the three long arms of TLC1, which connect essential and important accessory protein subunits $\mathrm{Ku}$, Est1, and $\mathrm{Sm}_{7}$, to its central catalytic hub. This 956-nt triple-stiff-arm TLC1 (TSA-T) reconstitutes active telomerase with TERT (Est2) in vitro. Furthermore, TSA-T functions in vivo, even maintaining longer telomeres than TLC1 on a per RNA basis. We also tested functional contributions of each stiffened arm within TSA-T and found that the stiffened Est1 and Ku arms contribute to telomere lengthening, while stiffening the terminal arm reduces telomere length and telomerase RNA abundance. The fact that yeast telomerase tolerates significant stiffening of its RNA subunit in vivo advances our understanding of the architectural and functional organization of this RNP and, more broadly, our conception of the world of IncRNPs.
\end{abstract}

Keywords: telomerase; RNA; RNP; scaffold; yeast

\section{INTRODUCTION}

Eukaryotes contend with the chromosome end-replication problem because DNA polymerases cannot fully replicate linear DNA termini (Blackburn 2006). This results in chromosome ends eroding at each S phase, and, eventually, the triggering of the $\mathrm{G}_{2} / \mathrm{M}$ cellular senescence checkpoint, instigated by critically short telomeres (Sandell and Zakian 1993). Most eukaryotes counteract the end-replication problem by expressing the specialized DNA-synthesizing ribonucleoprotein (RNP) enzyme telomerase at least at some stage of their life cycle. The core consists of telomerase reverse transcriptase (TERT) and an RNA subunit (TR), which contains a short stretch of nucleotides that act as a template for TERT-catalyzed reverse transcription (Shippen-Lentz and Blackburn 1990). TR also binds other protein subunits (Lendvay et al. 1996; Livengood et al. 2002; Seto et al. 2003), functions as a flexible scaffold for telomerase RNP assembly (Zappulla and Cech 2004), and coordinates with TERT in catalysis (Richards et al. 2006; Stone et al. 2007;

\footnotetext{
${ }^{1}$ Corresponding author

E-mail zappulla@jhu.edu

Article published online ahead of print. Article and publication date are at http://www.rnajournal.org/cgi/doi/10.1261/rna.033555.112.
}

Robart et al. 2010; Berman et al. 2011). While TERT is rather well conserved, the telomerase RNA is evolving extraordinarily rapidly, both in size and sequence. The length of TR ranges from $\sim 150 \mathrm{nt}$ in some ciliates to 451 in humans and $>2000$ in some fungi (Greider and Blackburn 1989; Singer and Gottschling 1994; Feng et al. 1995; Zaug et al. 1996; Kachouri-Lafond et al. 2009), and the sequence seems completely different between these evolutionary clades, although a few secondary/tertiary structural elements are common to almost all telomerase RNAs (Lin et al. 2004).

In the budding yeast Saccharomyces cerevisiae, the telomerase RNA, TLC1, is an 1157-nt-long noncoding RNA (lncRNA) shown to form a "Y" -shaped overall secondary structure (Dandjinou et al. 2004; Zappulla and Cech 2004). Yeast TERT, Est2 (Ever-shorter telomeres 2), binds near the central core region of the RNA (Livengood et al. 2002) where the three long "arms" converge by the template region (see Fig. 1; Greider and Blackburn 1989; Singer and Gottschling 1994; Dandjinou et al. 2004; Zappulla and Cech 2004). Together, Est 2 and TLC1 form the minimal telomerase catalytic core required for activity in vitro (Zappulla et al. 2005), demonstrating that the yeast core enzyme composition is conserved with telomerase of ciliates and mammals (Autexier and Greider 1994; Weinrich et al. 


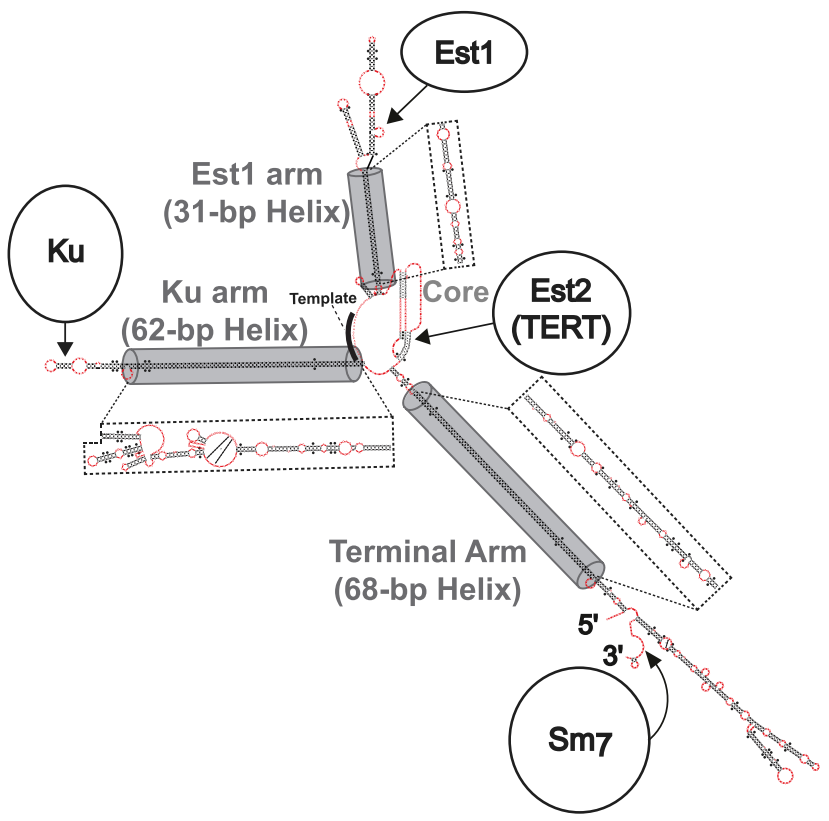

FIGURE 1. A yeast telomerase RNA with three stiffened arms, "Triple Stiff Arm TLC1" (TSA-T), designed based on the secondary structure model for wild type. The secondary structures of the wildtype arms are indicated (boxes) next to the stiffened arms (gray cylinders) of TSA-T. The length and width of the dsRNA cylinders convey proportions for A-form RNA double helices (Jang et al. 1998) and are drawn approximately to scale with the proteins (Zappulla and Cech 2006) based on crystal structure models of homologsT. castaneum TERT (Est2) (Gillis et al. 2008), human Ku (Walker et al. 2001), and human $\mathrm{Sm}_{7}$ (Leung et al. 2011). (Red) Unpaired

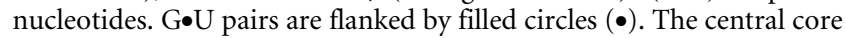
displayed is based on published models (Dandjinou et al. 2004; Lin et al. 2004; Zappulla and Cech 2004; Qiao and Cech 2008; Zappulla et al. 2011), while the heavily mutated arms are the lowest-energy Mfold prediction.

1997). In vivo, however, several accessory proteins/protein complexes, in addition to Est2, bind to telomerase RNA to form the RNP holoenzyme. These include Est1, the $\mathrm{Ku}$ heterodimer, and the $\mathrm{Sm}_{7}$ heteroheptamer, each of which binds close to the end of a different arm of TLC1 (Seto et al. 1999; Peterson et al. 2001; Seto et al. 2002; Stellwagen et al. 2003). Est1 binding to TLC1 is essential for telomere maintenance; the best-characterized function of Est1 is recruiting telomerase to chromosome ends through its interaction with the telomeric DNA-binding protein Cdc13 (Virta-Pearlman et al. 1996; Zhou et al. 2000; Bianchi et al. 2004). Ku and $\mathrm{Sm}_{7}$ are important, but not essential, for telomerase function. Loss of $\mathrm{Ku}$ binding to TLC1 results in shortened telomeres (Peterson et al. 2001; Bertuch and Lundblad 2003; Stellwagen et al. 2003) (in addition to a 50\% drop in TLC1 abundance [Zappulla et al. 2011]), and $\mathrm{Ku}$ has been reported to bind telomeres (Gravel et al. 1998). These findings, as well as other studies, have suggested that $\mathrm{Ku}$ helps to recruit telomerase to telomeres in yeast by sequentially binding DNA and TLC1 RNA (Stellwagen et al. 2003; Pfingsten et al. 2012). The $\mathrm{Sm}_{7}$ complex, best known for binding snRNAs, is involved in
TLC1 biogenesis; disrupting the $\mathrm{Sm}_{7}-\mathrm{TLC} 1$ interaction results in an $\sim 20$-fold drop in abundance of the mature form of TLC1 RNA and very short telomeres (Seto et al. 1999). An additional subunit of the telomerase RNP is the Est3 protein, which has an unknown essential function in telomere maintenance (Lendvay et al. 1996; Hughes et al. 2000). Est3 does not appear to bind directly to TLC1, but rather is associated with the RNP through interactions with Est2 (Talley et al. 2011).

The Est1, $\mathrm{Ku}$, and $\mathrm{Sm}_{7}$ accessory proteins bind to the conserved elements at the ends of each of the different TLC1 arms. These telomerase holoenzyme protein subunits do not appear to bind other regions of the RNA, to each other, or to Est2. The conserved accessory subunit-binding sites are located toward the periphery of the Y-shaped RNA secondary structure, with vast stretches of rapidly evolving RNA in between, seemingly devoid of any specific proteinbinding sites (Dandjinou et al. 2004; Zappulla and Cech 2004). Overall, $57 \%$ of TLC1 RNA nucleotides differ among four species of the Saccharomyces genus (compared with just $1 \%-18 \%$ of other essential ncRNAs) (Zappulla and Cech 2004). The variation among the nucleotides in the central portions of the arms is even greater, with $62 \%$ varying between the same closely related species (Zappulla and Cech 2004). The majority of these nucleotides in the arms have been shown to be dispensable for basal telomerase activity; a miniature TLC1 (Mini-T) with 657 nt deleted from the arms is functional in vitro and is able to maintain short but functional telomeres in vivo (Zappulla et al. 2005). Furthermore, the Est 1 and $\mathrm{Ku}$ accessory subunit-binding sites on the arms of TLC1 can be repositioned on the RNA and still function (Zappulla and Cech 2004; Zappulla et al. 2011).

This permissiveness of TLC1 to relocation of proteinbinding sites and to significant truncation of arms supports the flexible scaffold model of yeast telomerase RNA (Zappulla and Cech 2004, 2006; Zappulla et al. 2011). TLC1 has been shown to be functionally flexible, in that functional modules (i.e., protein subunit-binding sites) can be relocated on the primary and secondary structure of the scaffold without elimination of activity. This contrasts starkly with RNA structure and function in well-studied RNPs such as the ribosome, where essentially the entire RNA complex, composed of $\sim 5500 \mathrm{nt}$ in S. cerevisiae, is highly structured (Verschoor et al. 1998; Ban et al. 2000; Moore and Steitz 2002).

Many aspects of telomerase mechanism remain unclear. Although steps have been made toward understanding how telomerase RNAs help coordinate with TERT during core enzyme activity in vitro (Richards et al. 2006; Stone et al. 2007; Qiao and Cech 2008; Robart et al. 2010; Berman et al. 2011), it is not known if telomerase RNA coordinates the essential and important accessory protein subunits for functions of the RNP holoenzyme. TLC1 may act as a simple scaffold, with no precise spatial orientation of accessory subunits necessary; i.e., the accessory protein subunits may 
be tethered by RNA and function as "beads on a string." On the other hand, holoenzyme protein subunits may need to ultimately occupy a precise position within the RNP to provide function. This could hypothetically be achieved by the RNA tethering the protein subunits to the RNP through a physically flexible appendage, allowing the proteins to then subsequently dock into their active sites in the complex.

Physical flexibility of yeast telomerase RNA is implied by the many bulges and internal loops in the extended arms of its secondary structure model, as well as the astonishingly rapid evolution of its sequence. The importance of this apparent physical flexibility to telomerase action has not been directly examined. The RNA arms of TLC1 are potentially very physically flexible due to $42 \%$ of the nucleotides in the $\mathrm{Ku}$ arm, 32\% in the Est1 arm, and 32\% in the terminal arm predicted to be unpaired, present in RNA internal loops and bulges (see Fig. 1). Unpaired nucleotides can potentially confer great flexibility to RNA, allowing the structure to bend, with the bulges acting as hinges (Bhattacharyya and Lilley 1989; Zacharias and Hagerman 1996; Fulle and Gohlke 2009). The doublestranded RNA (dsRNA) helix, on the other hand, is quite rigid (Hagerman 1997). A measure of this physical parameter is "persistence length," the distance over which the axis of a polymer will tend to persist without significant bending. RNA double helices are more rigid than those formed by DNA, in part due to their wider A-form helical geometry. The persistence length for B-form dsDNA helix is $\sim 50 \mathrm{~nm}$, or 150 bp (Bustamante et al. 2000), whereas for an A-form dsRNA helix, the persistence length is $63 \mathrm{~nm}$, or $225 \mathrm{bp}$ (Abels et al. 2005). It is important to note that nucleic acids shorter than their persistence length are not absolutely rigid and that bends can be induced through protein binding or long-distance interactions (Hagerman 1988; Cloutier and Widom 2004; Wiggins and Nelson 2006; Wiggins et al. 2006). However, helical RNA has reduced flexibility compared with bulged RNA and tends to remain stiff when significantly shorter than the persistence length (Mastroianni et al. 2009).

Here, we describe TLC1 variants engineered such that the physical flexibility of the three RNA arms is predicted to be severely constrained by converting the RNA between the central catalytic core and the binding sites for $\mathrm{Ku}$, Est1, and $\mathrm{Sm}_{7}$ into a short, rod-like, uninterrupted double helix. We show that this 956-nt "triple-stiff-arm TLC1," TSA-T, folds stably in vitro and reconstitutes active telomerase with Est2. Furthermore, TSA-T is able to function in vivo, maintaining telomere length $77 \%$ that of wild type, despite the RNA being only $15 \%$ as abundant. We demonstrate that this low accumulation of TSA-T is responsible for the shortened telomere phenotype, and that, on a per RNA basis, TSA-T actually maintains longer telomeres than wild type. Furthermore, introducing rigidity specifically into the $\mathrm{Ku}$ and Est 1 arms promotes telomere elongation, while in the terminal arm it leads to telomere shortening. Thus, the yeast telomerase RNP enzyme functions despite all known essential and important accessory RNA-binding subunits being held away from its catalytic core by dsRNA "struts," providing physical evidence for a simple scaffold model for the RNA subunit's function.

\section{RESULTS}

\section{Design of a yeast telomerase RNA with all three arms stiffened}

Using the TLC1 secondary structure model (Dandjinou et al. 2004; Zappulla and Cech 2004) and also the previously described miniature telomerase RNA (Mini-T) (Zappulla et al. 2005) as a guide, we engineered a highly modified TLC1 with the precise removal of all of the bulges and loops from the bulk of the arms (Fig. 1; Supplemental Fig. S1). In addition, we changed 22 uracil (U) residues involved in $\mathrm{G} \bullet \mathrm{U}$ pairs in these regions to $\mathrm{C}$, to provide almost entirely canonical Watson-Crick base pairing as part of the arm-stiffening process (one G•U pair was left in each arm proximal to the core to create a specific unique restriction site for future subcloning, and a few remaining $\mathrm{G} \bullet \mathrm{U}$ pairs were unchanged near proposed protein-binding sites). We used $M$ fold RNAfolding prediction software to help avoid misfolded structures and increase the chance that the RNA would fold as designed (Supplemental Fig. S1). The resulting 956-nt "triple-stiff-arm TLC1" (TSA-T) RNA is predicted to form $62 \mathrm{bp}$ of uninterrupted double helix in the $\mathrm{Ku}$ arm, $31 \mathrm{bp}$ in the Est1 arm, and $68 \mathrm{bp}$ in the terminal arm. Because each of these paired regions is $<30 \%$ the persistence length of helical RNA (Abels et al. 2005), the dsRNA regions of the arms of TSA-T should act as semi-rigid rods.

Mfold RNA secondary structure modeling suggests that $72 \%$ of the $956 \mathrm{nt}$ in TSA-T will be base-paired, compared with $61 \%$ paired in the Mfold model for 1157-nt wild-type TLC1 and 58\% in the 500-nt Mini-T (Supplemental Fig. S1). Accordingly, the predicted folding of TSA-T is more energetically favorable than TLC1 or Mini-T: -458 $\mathrm{kcal} / \mathrm{mol}$, compared with $-321 \mathrm{kcal} / \mathrm{mol}$ for wild-type TLC1 and $-133 \mathrm{kcal} / \mathrm{mol}$ for Mini-T (500) (Supplemental Fig. S2).

\section{Triple-stiff-arm telomerase RNA, TSA-T, reconstitutes enzyme activity in vitro}

TSA-T RNA is predicted to form an extremely stable secondary structure because of its almost entirely doublehelical arms. To test if these energetically favored arms form in vitro as designed, we synthesized TSA-T using T7 RNA polymerase in the presence of $\left[\alpha-{ }^{32} \mathrm{P}\right] \mathrm{GTP}$, digested it extensively with single-stranded RNA-digesting nucleases RNase A and RNase T1, and then analyzed protected products by denaturing polyacrylamide-urea gel electrophoresis (Fig. 2A). Wild-type TLC1 and Mini-T(500) RNAs were also analyzed in parallel by the same method. When examined by polyacrylamide-urea gel electrophoresis, the 


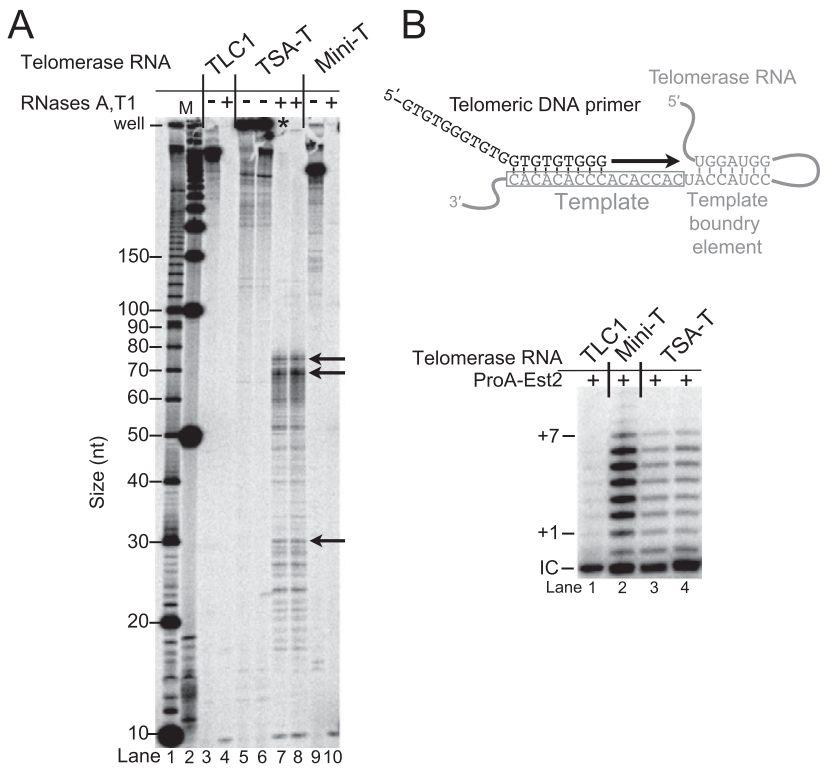

FIGURE 2. TSA-T telomerase RNA folds stably and functions in vitro. (A) TSA-T contains RNase-resistant structures in vitro. An RNase protection assay was performed on $\left[\alpha-{ }^{32} \mathrm{P}\right] \mathrm{GTP}$-labeled TSA-T (956 nt), TLC1 (1157 nt), and Mini-T (500 nt), by extensively digesting the T7-transcribed RNAs with RNase A and RNase T1. Digestion reaction products were resolved by polyacrylamide/urea gel electrophoresis. The bulk of full-length TSA-T is reproducibly trapped in the wells, presumably because the long helical regions are resistant to complete denaturation, resulting in a semi-folded RNA conformation (TSA-T ${ }^{\star}$, indicated by ${ }^{*}$ on the gel) that has greatly reduced mobility in PAGE. (Arrows) Bands that likely correspond to protected dsRNA arms of TSA-T. (M) Heat-denatured, $\left[\gamma^{32} \mathrm{P}\right]$-labeled DNA markers; (lane 1) $10 \mathrm{bp}$; (lane 2) $50 \mathrm{bp}$. (B) TSA-T reconstitutes telomerase activity when coexpressed with ProA-Est2 (TERT) in rabbit reticulocyte lysates (Zappulla et al. 2005). Like Mini-T, TSA-T was able to form an active telomerase RNP, adding $7 \mathrm{nt}(+1$ through +7 ) to the telomeric DNA primer (shown above). (Lanes 3 and 4) Independently generated TSA-Telomerase preparations and telomerase assays. (IC) Internal control: $\sim 1 \mathrm{nM}\left[\gamma^{-32} \mathrm{P}\right]$-labeled primer added before telomerase reaction serves as internal control for product recovery and loading onto the gel.

bulk of 956-nt TSA-T molecules do not migrate into the gel matrix, unlike wild-type 1157-nt TLC1 and 500-nt Mini-T RNA. The immobility of TSA-T under these electrophoretic conditions suggests that the TSA-T arms fold sufficiently stably that they are not denatured, and the semi-folded RNA $\left(\mathrm{TSA}^{*} \mathrm{~T}^{*}\right.$ ) has an overall topology that does not migrate well through polyacrylamide (e.g., the structure shown in Fig. 1 with only the stiffened regions remaining paired, trapping the central core as a 178-nt internal loop). Furthermore, we find that although RNase treatment essentially completely digests TLC1 and Mini-T (Fig. 2A, lanes 4,10), the same treatment does not completely digest TSA-T: A collection of prominent RNase-resistant bands from TSA-T are reproducibly observed over the range of $\sim 20-72 \mathrm{nt}$ (Fig. 2A, lanes 7,8 ), based on denatured DNA ladders. The two slowest-migrating bands are consistent with expected longest dsRNA sections of the terminal and $\mathrm{Ku}$ arms of TSA-T (68 and $62 \mathrm{bp}$, respectively) (see the top two arrows in Fig. 2A). Furthermore, one of the faster-migrating bands is consistent with the expected size for the 31-bp Est1 arm helix (see bottom arrow in Fig. 2A). Low-intensity bands shorter than the largest protected fragment likely represent partial digestion products.

To analyze TSA-T functionality in vitro, we tested if it can form an enzymatically active RNP complex with Est2 using the reconstituted yeast telomerase assay (Zappulla et al. 2005). For function in vitro, yeast telomerase RNA must have the ssRNA template loop (Prescott and Blackburn 1997), template boundary element formed by long-range pairing (Tzfati et al. 2000; Seto et al. 2003), and the pseudoknot with its embedded base triples (Tzfati et al. 2003; Lin et al. 2004; Qiao and Cech 2008). TSA-T RNA was coexpressed with protein A (ProA)-tagged Est2 in a rabbit reticulocyte lysate transcription and translation system, immunopurified, and tested for activity on a telomeric DNA primer. TSA-Telomerase (i.e., TSA-T•ProAEst2 complex) reproducibly lengthens the DNA primer with a similar pattern to that of Mini-Telomerase (Zappulla et al. 2005), albeit with about fivefold less activity (Fig. 2B). The activity of TSA-T in the reconstituted telomerase assay is still much greater than the $\sim 1.2$-kb wild-type TLC1, which, most likely due to the existence of many alternate folding conformations, is essentially nonfunctional when synthesized in vitro (Zappulla et al. 2005) (although in our current experiments we occasionally observe some very weak activity) (see Figs. 2B and 5B below). Thus, the central core of TSA-T folds properly in vitro, binds to Est2, and coordinates with it appropriately to reconstitute telomerase activity.

\section{TSA-T telomerase RNA supports a highly functional RNP holoenzyme in vivo}

We have demonstrated that TSA-T can successfully interact with Est2 to form an active catalytic core when produced in rabbit reticulocyte lysates in vitro. However, in vivo, several accessory proteins must interact with telomerase RNA, including the essential Est1 and the important $\mathrm{Ku}$ and $\mathrm{Sm}_{7}$ subunits (Seto et al. 1999, 2002; Peterson et al. 2001; Stellwagen et al. 2003; Zappulla et al. 2011). We next investigated whether TSA-T is able to form a functional telomerase holoenzyme in vivo, by testing if TSA-T complements a tlc1s mutant. We transformed a centromere-containing plasmid harboring the TSA-T gene (with endogenous TLC1 upstream and downstream sequences)

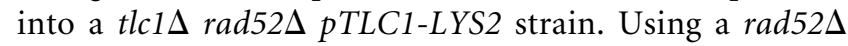
genetic background prevents initiation of the alternative "survivor" pathway for telomere lengthening, providing a clear-cut method for assessing telomerase functionality in vivo (Lundblad and Blackburn 1993; Li and Lustig 1996; McEachern and Blackburn 1996; Le et al. 1999). After shuffling out the LYS2-marked wild-type TLC1 
cover plasmid by counterselection on medium containing $\alpha$-aminoadipate, the TSA-T cells were restreaked 10 times ( $\sim 250$ generations). Telomeres in yeast cells without functional telomerase shorten with each cell cycle, eventually resulting in a $G_{2} / M$ arrest known as senescence, by 75-100 generations (Lundblad and Szostak 1989; Singer and Gottschling 1994). TSA-Texpressing cells grew like wild type through the entirety of the experiment (Fig. 3A). Thus, telomerase RNA with the bulk of all three of its long arms converted to dsRNA functions in vivo.

Next, we examined telomere length in cells expressing TSA-T. Southern blotting of XhoI-digested genomic DNA using a telomeric probe showed telomeres $76 \pm 14 \mathrm{bp}$ shorter in TSA-T cells than wild type after 250 generations. We calculate that average telomere length in TSA-T cells is therefore $\sim 248 \mathrm{bp}$, or $77 \%$ of wild-type telomere length for this strain $(\sim 320$ bp) (Fig. $3 \mathrm{~B})$. The telomere length decrease in TSA-T cells is moderate but statistically significant $(p=0.0006)$; other TLC1 alleles are known to have more dramatically shortened telomeres. For example, Mini$T(500)$ maintains telomeres $231 \pm 25$ bp shorter than wild type at generation $250, \sim 28 \%$ of estimated wild-type length (Fig. 3B).

The moderately shortened telomeres observed in TSA-T-expressing cells could be partially or completely explained by a low abundance of the RNA as compared with TLC1-expressing cells. Total RNA spotted on a membrane was probed in parallel for a $3^{\prime}$ region of TLC1 (nucleotides 906-1140), which is also present in TSA-T. Since this region is wild type in TSA-T, probes are expected to bind equally well to TLC1 and TSA-T. We calculate the RNA abundance of TSA-T in cells to be $\sim 15 \% \pm 2 \%$ of wild-type TLC1 (Fig. 3C).

It is noteworthy that triple-stiff-arm TLC1, while only $15 \%$ as abundant as TLC1, is able to maintain telomeres only 76 bp shorter. In contrast, although Mini-T(500) RNA abundance is similarly $\sim 16 \%$ of wild type (Zappulla et al. 2005), it maintains telomeres that are 231 bp shorter. We hypothesized that the reduced TSA-T RNA abundance contributed to the shorter telomeres in these cells. To compare TSA-T to TLC1 at the same RNA abundance, we expressed TSA-T from a high-copy, $2 \mu$ plasmid, versus two copies of $T L C 1$ on a single CEN plasmid in a tlc1S strain.
This raised TSA-T abundance to $181 \%$ of wild type and TLC1 levels to $187 \%$ (Fig. 4A). We found that TSA-T on a $2 \mu$ plasmid maintains telomeres $97 \pm 14$ bp longer than wild type, while two copies of TLC1 on a CEN plasmid only increased telomere length by $29 \pm 5 \mathrm{bp}$, a statistically significant difference ( $p=0.01$ ) (Fig. 4B). Furthermore, we were able to rescue telomere length by simply expressing two copies of TSA-T on a single CEN plasmid. This raises TSA-T abundance from $12 \%$ to $23 \%$, resulting in telomeres statistically indistinguishable from wild type (Fig. 4A,B). These data demonstrate that TSA-T maintains longer telomeres in yeast cells than TLC1 when accounting for RNA abundance, and suggest that TSA-T could be viewed as a gain-of-function telomerase RNA allele with respect to telomere lengthening. 
A

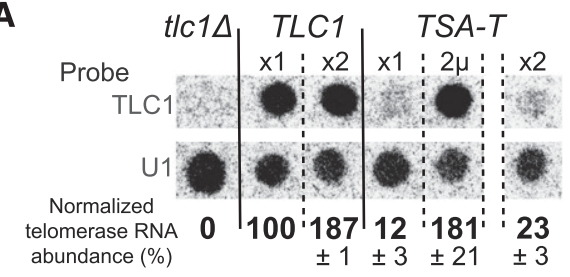

B

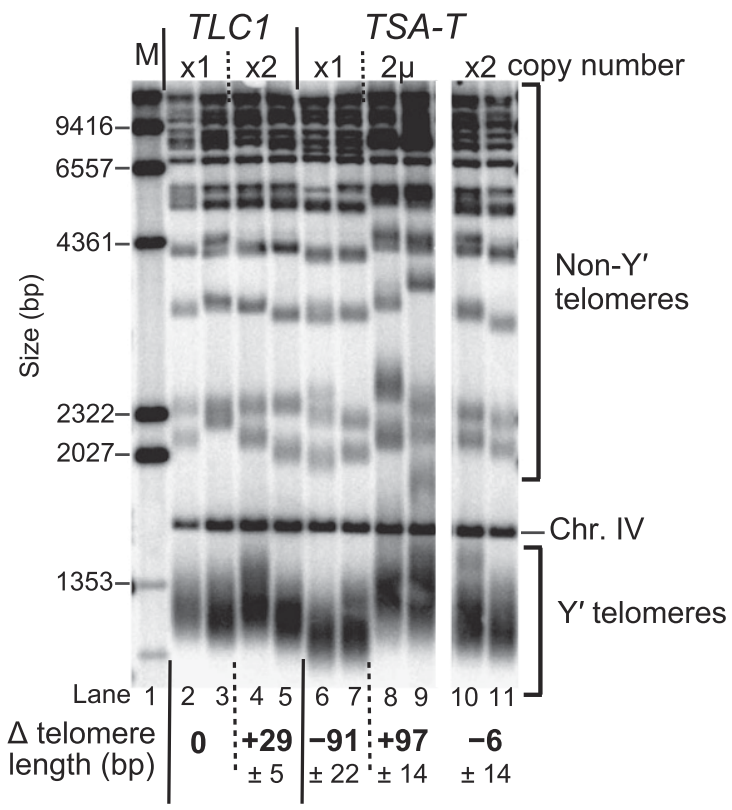

FIGURE 4. TSA-T supports longer telomeres than wild-type TLC1 when accounting for RNA abundance. (A) Dot blot of TLC1 and TSA-T RNAs under different expression conditions. TLC1 was expressed from a single copy of the TLC1 gene on a CEN plasmid (x1), or from a single $C E N$ plasmid with two tandem copies of TLC1 (x2). TSA-T was similarly expressed from a single-copy gene (x1) or two tandem copies of TSA-T on a CEN plasmid (x2). TSA-T was also expressed from a high-copy $2 \mu$ plasmid. Note that the strain background used for this experiment (W303) is different from the strain used to generate the data in Figure 3 (S288C). The blot was performed as previously described in Figure 3C. Total RNA is shown from the 250generation time point. Average relative RNA abundance from four independent isolates after 250 generations of growth is indicated \pm SEM. (B) TSA-T supports longer telomeres than wild-type TLC1 when accounting for RNA abundance. A telomere Southern blot was performed on genomic DNA isolated from cells expressing TLC1 or TSA-T from single-gene (x1) or duplicate-gene (x2) CEN plasmids, as well as TSA-T from a $2 \mu$ plasmid. Two independent transformants are shown for each condition. Average changes in $\mathrm{Y}^{\prime}$ telomere length from four independent isolates after 250 generations of growth are indicated \pm SEM.

\section{The stiffened Ku and Est1 arms of TSA-T promote telomere elongation while a stiffened terminal arm leads to low RNA abundance and short telomeres}

To determine how each stiffened arm contributes to TSA-T phenotypes, we made constructs with each individual arm stiffened. Furthermore, we constructed alleles with each pairwise combination of stiffened arms to test their genetic interactions. These TLC1 alleles are named based on the status of the $\mathrm{Ku}$, Est1, and terminal arms, respectively: "-" indicates the arm is wild type, while " $\mathrm{S}$ " indicates it is stiffened (Fig. 5A). We first tested which combinations of stiffened arms promote reconstituted telomerase activity in vitro relative to the 1157-nt wild-type TLC1 RNA, which performs poorly in these conditions, presumably due to misfolding. Each TSA-T allele was coexpressed with ProAEst2, as done previously (Zappulla et al. 2005), and activity was normalized to the level of $\left[{ }^{32} \mathrm{~S}\right]$-ProA-Est2 recovered. As observed earlier (Fig. 2B), TSA-Telomerase has nearly 10-fold more activity than wild-type TLC1 (Fig. 5B, cf. lanes 2 and 3). We found that alleles with stiffened $\mathrm{Ku}$ or terminal arms have greater activity than TLC1 (Fig. 5B, cf. lane 2 with lanes 3,4,6-8), while stiffening the Est1 arm does not have a significant effect on enzymatic activity (Fig. $5 \mathrm{~B}$, lane 5).

Next, we determined the effects of each stiffened arm on telomerase in vivo. We expressed each stiffened-arm telomerase RNA allele from a centromeric plasmid in a $t c 1 \Delta$ strain and grew cells for 250 generations. All stiffened-arm RNA alleles are able to complement a loss of wild-type TLC1 (Fig. 6A). To ascertain which stiffened arms affect telomerase RNA levels in the cell, we isolated total cellular RNA and performed dot blots. We found that stiffening the terminal arm dramatically reduces telomerase RNA abundance in the cell, resulting in levels $10 \%-13 \%$ of wild-type TLC1 (Fig. 6B). The stiffened Ku and Est1 arms also reduce telomerase RNA levels, although to a lesser degree.

We used Southern blots to measure telomere length in cells expressing stiffened-arm TLC1 permutations from CEN plasmids, to determine which arm or set of arms is responsible for the increased telomere length maintenance activity for TSA-T. The construct with stiffened $\mathrm{Ku}$ and Est 1 arms (S S-) maintains telomeres $77 \pm 24$ bp longer than wild type $(p=0.05)$ (Fig. $6 \mathrm{C}$, lanes 12,13). The stiffened Est1 arm alone $(-S-)$ causes a small increase in telomere length, $23 \pm 12$ bp. With four biological replicates, this increase is not quite statistically significant $(p=0.15$; lanes 8,9$)$. Stiffening the $\mathrm{Ku}$ arm alone $\left(\mathrm{S}_{--}\right)$ also results in no significant change $(p=0.9$; lanes 6,7$)$. Meanwhile, all constructs with a stiffened terminal arm $(--S, S-S,-S S$, and SSS) maintain telomeres shorter than wild type and stiffening the terminal arm per se $(--S)$ results in telomeres $139 \pm 6$ bp shorter $(p=0.0002$; lanes $10,11)$. These shortened telomeres are likely the result of very low RNA abundance for stiffened terminal arm alleles (Fig. 6B). All of the stiffened arm constructs, however, maintain telomeres longer than the miniaturized telomerase RNA Mini-T(500).

\section{DISCUSSION}

Telomerase RNA (TR) contributes far more than a template for enzymatic function. In vitro, the conserved roles of the telomerase long noncoding RNA (lncRNA) subunit in core 


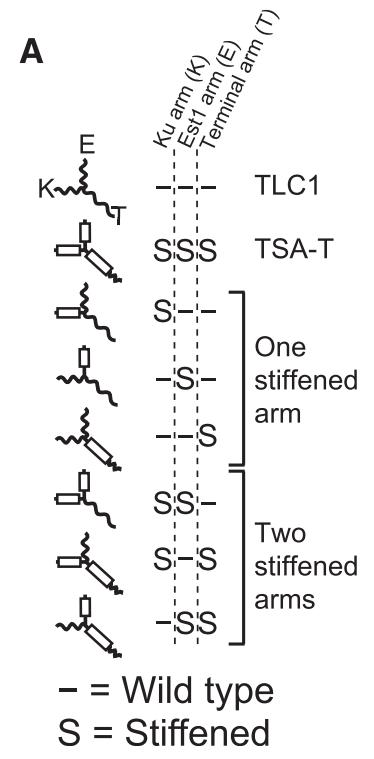

B

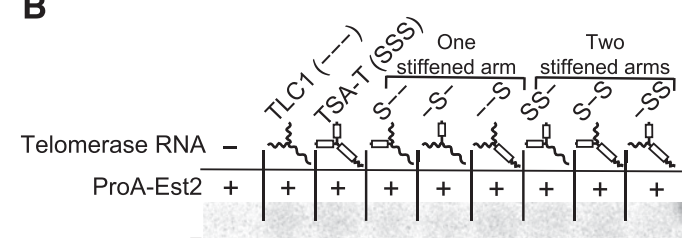

$+7$

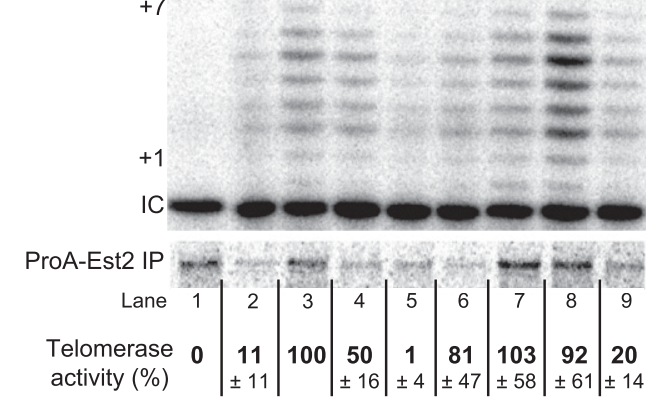

FIGURE 5. Effects of stiffening particular arms of telomerase RNA on reconstituting active enzyme. (A) Variations of yeast telomerase RNA with all possible combinations of wild-type or stiffened arms from TSA-T were made, including one- and two-stiffened-arm RNAs. In the schematics shown, wavy black lines represent wild-type arms, while white cylinders denote stiffening. (B) Stiffening the Ku or terminal arms in yeast telomerase RNA promotes activity in vitro. Activity levels were normalized to an internal control for recovery and loading (IC, $\left[\gamma^{-}{ }^{32} \mathrm{P}\right]$-labeled primer), and to immunopurified $\left[{ }^{35} \mathrm{~S}\right]$ Met-labeled ProA-Est2 levels. Percent activity relative to TSA-T is shown \pm SEM from three replicates.

enzyme function also include providing a $5^{\prime}$ boundary of the template region for appropriate reverse transcription (Tzfati et al. 2000; Lai et al. 2002; Chen and Greider 2003; Seto et al. 2003) and binding and coordinating TERT during catalysis (Bryan et al. 2000; Lai et al. 2003; Stone et al. 2007; Berman et al. 2011). Furthermore, in vivo, telomerase RNA provides a scaffold for the assembly and function of essential and important holoenzyme protein subunits (Est1, $\mathrm{Ku}$, and $\mathrm{Sm}_{7}$ ) (Cech 2004; Blackburn and Collins 2011).

Using the tractable $S$. cerevisiae model organism, it has been shown that the TLC1 telomerase RNA scaffolding is functionally flexible (Zappulla and Cech 2006), given that Est1- and Ku-binding sites can be dramatically repositioned in the RNA with significant retention of their essential and important in vivo functions, respectively (Zappulla and Cech 2004; Zappulla et al. 2011). Identification of functionally flexible scaffolding by yeast telomerase RNA has provided a prototype for a mechanism that is potentially applicable to a rapidly growing list of lncRNAs (Guttman et al. 2011; Wang and Chang 2011). However, much more remains to be understood about how telomerase RNA might contribute to the mechanism of this enzymatic lncRNP. Although the secondary structure model for TLC1 shows many bulges and loops throughout its 1157-nt length (Dandjinou et al. 2004; Zappulla and Cech 2004), it is not known if the RNA is indeed physically flexible, nor if the potential flexibility, hinging on these loops and bulges, is important. The 1157-nt wild-type TLC1 RNA does not fold appreciably into an active conformation in vitro (Figs. 2A and 5B), making structural characterization very difficult. Miniaturized telomerase (Mini-T) RNAs reconstitute activity with TERT in rabbit reticulocyte lysates (Zappulla et al. 2005), but these RNAs range from 657 to 773 nt shorter than wild-type TLC1 and are missing the bulk of all three long arms.

In the present study, we design and create a TLC1 allele with significantly stiffened arms, by removing unpaired nucleotides within them, leaving only dsRNA (Fig. 1), which has been determined to be rigid when shorter than 225 bp (Abels et al. 2005). Triple-stiff-arm TLC1, TSA-T, differs from Mini-T(500) in that the regions excised to make Mini- $T$ are instead rigidified by removal of unpaired bases, and also the distal portion of the terminal arm in TSA-T is left intact. Stiffening the three arms that emanate from the catalytic core significantly constrains the structural freedom within the RNP. Unlike in Mini-T, where the arm tip-binding holoenzyme protein subunits-Est1, $\mathrm{Ku}$, and $\mathrm{Sm}_{7}$-are moved closer to the catalytic core, these accessory subunits are predicted to be inhibited from flexing toward the central core by the intervening dsRNA in the arms of TSA-T. While the stiffened arms may still retain some reduced ability to flex, the position of each accessory protein relative to the rest of the RNP is much more constrained than in wild type. Thus, TSA-T is expected to have an unperturbed catalytic core (where Est2 binds) and holoenzyme subunits, Est1, Ku, and $\mathrm{Sm}_{7}$, held at a distance by stiff dsRNA struts.

In many organisms other than Saccharomyces, the 31- to 68-bp tracts of dsRNA in TSA-T would be targeted by the RNA interference (RNAi) degradation pathway and could also alter gene expression. S. cerevisiae, however, lacks RNAi, since it does not have a Dicer enzyme homolog nor some of the other key components of RNAi machinery (Nakayashiki et al. 2006). Furthermore, TSA-T should be spared by the RNase III enzyme in Saccharomyces, since Rntl recognizes a consensus sequence in terminal loops instead of the RNA double helix (Chanfreau et al. 2000).

With the removal of 201 unpaired nucleotides, TSA-T folding is energetically more favorable than wild-type TLC1: Mfold RNA secondary structure prediction software calculates the minimum free energy $(\Delta G)$ to be $-458 \mathrm{kcal} /$ mol for TSA-T, compared with $-321 \mathrm{kcal} / \mathrm{mol}$ for TLC1 (Supplemental Fig. S2). When normalized for RNA length, this calculated free energy difference $(\Delta \Delta G)$ between TSA-T 


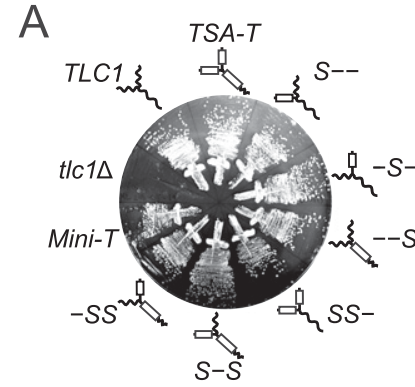

250 Generations
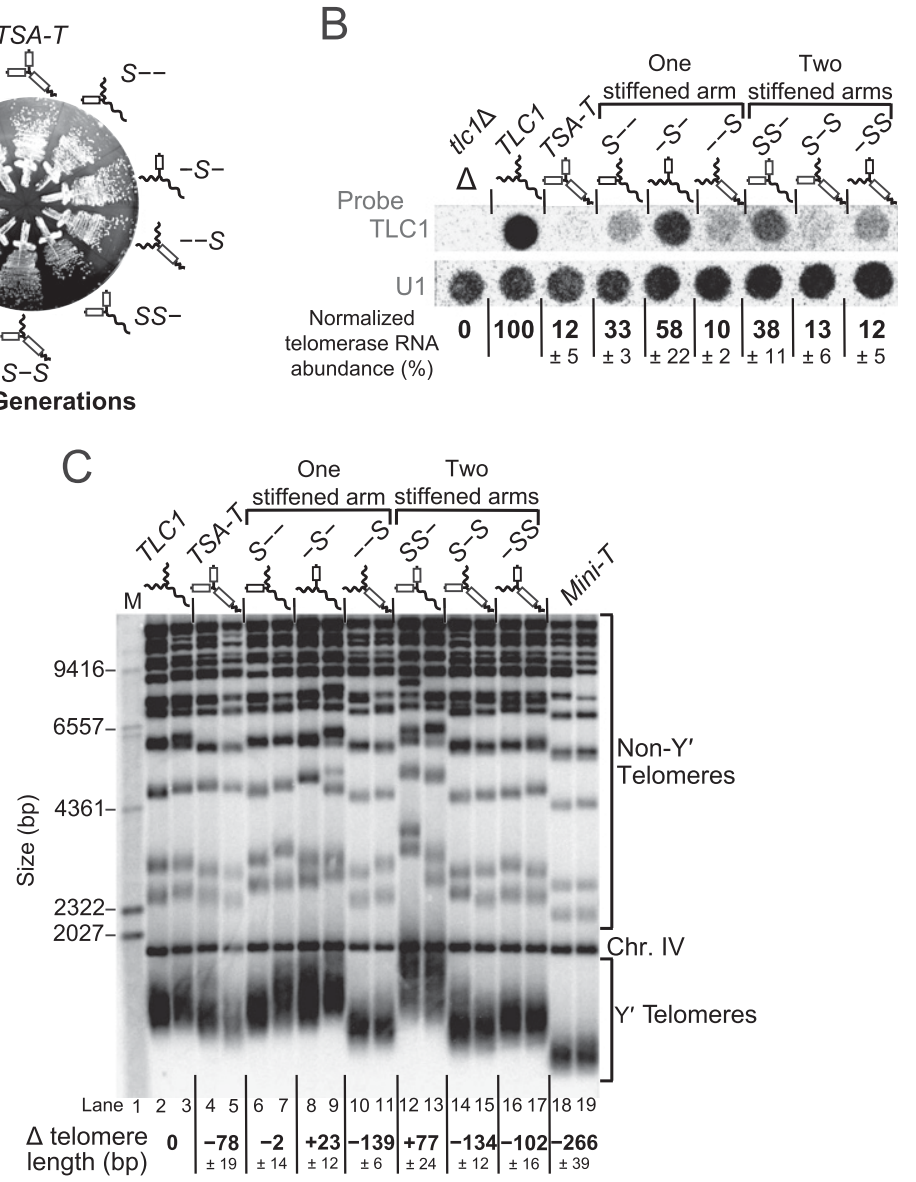

FIGURE 6. Effects of stiffening arms of yeast telomerase RNA individually and in each pairwise combination on cell growth, RNA abundance, and telomere length. $(A)$ All stiffenedarm TLC1 constructs are able to support yeast cell proliferation. Each telomerase RNA allele was harbored on a low-copy CEN plasmid in a $t l c 1 \Delta$ yeast strain, and restreaked for more than 250 generations. (B) Stiffening telomerase RNA arms lowers RNA abundance. Telomerase RNA levels from cells expressing stiff-arm TLC1 constructs after 250 generations of growth were determined by dot blot. Average relative RNA abundance is indicated for four biological replicates after 250 generations of growth, \pm SEM. (C) Stiffened Ku and Est1 arms together promote telomere lengthening, whereas a stiffened terminal arm leads to shortening. Telomere lengths from cells expressing stiff-arm TLC1 constructs were examined by Southern blot. Two isolates at 250 generations shown for each sample. Average change in $\mathrm{Y}^{\prime}$ telomere length is indicated for four biological replicates after 250 generations of growth, \pm SEM. supported by wild-type TLC1, although still about fivefold less than that by Mini-Telomerase.

The fact that TSA-T functions well in vitro suggests that the energetically favorable folding of its dsRNA arms promotes formation of an active conformation of the central core. However, in vivo, where arm-binding subunits are additionally required for telomerase function, it could not be assumed that TSA-T would be functional. Nevertheless, we find that TSA-T complements a $t l c 1 \Delta$ mutant and permits cell proliferation (Fig. 3A). The fact that TSA-T functions despite truncated, strut-like arms connecting Est $1, \mathrm{Ku}$, and $\mathrm{Sm}_{7}$ accessory subunits to the catalytic core provides further evidence that yeast telomerase RNA acts as a simple scaffold for these protein subunits.

We also showed that the abundance of TSA-T RNA in vivo is $15 \%$ of wildtype TLC1 (Fig. 3C). We detected TSA-T abundance by dot blots since it does not migrate appreciably in polyacrylamide-urea gels. This low electrophoretic mobility is ostensibly because its dsRNA arms resist denaturation by urea, consequently trapping the single-stranded 178-nt hub at the intersection of the three arms - this unwieldy topology would not be expected to migrate effectively through a polyacrylamide matrix.

The telomeres supported by TSA-T in yeast cells are 76 bp shorter than wild type. This phenotype contrasts with that of Mini-T(500) cells, which have telomeres that are 231 bp shorter (Fig. 3B). Thus, despite almost identical RNA abundance in the cell, TSA-T and Mini-T and TLC1 is $0.20 \mathrm{kcal} / \mathrm{mol}$ per nucleotide ( -0.48 vs. -0.28 $\mathrm{kcal} / \mathrm{mol}$ per nucleotide, respectively). In vitro, the dsRNA arms of TSA-T drive a highly stable structure that is resistant to denaturation by urea, and that contains regions protected from single-strand-specific RNA nucleases (Fig. 2A). Furthermore, the energetically favorable structure of TSA-T is functional in vitro, reconstituting activity when expressed in a transcription-translation system with TERT (Fig. 2B). Although TLC1 has been considered to be nonfunctional in reconstituted telomerase assays, we are able to reproducibly detect very low activity from TLC1 when reconstituted in rabbit reticulocyte lysates, thus allowing semi-quantitative comparison to Mini-T and TSA-T (Figs. 2B and 5B). TSAtelomerase activity appears to be $\geq 10$-fold more than that cells have very different telomere lengths. Furthermore, when the TSA-T RNA levels match those of TLC1 (181\% TSA-T vs. 187\% TLC1) (Fig. 4A), TSA-T cells have telomeres 97 bp longer than wild type, while TLC1 telomeres only increase by 29 bp (Fig. 4B). In addition, telomere length was restored to wild type by increasing TSA-T abundance from $12 \%$ to $23 \%$ of TLC1 (Fig. $4 \mathrm{~A}, \mathrm{~B}$ ). In other words, the telomere-shortening phenotype of TSA-T cells appears to be due to the reduction in telomerase RNA subunit abundance and, when normalized for RNA abundance, TSA-T can be considered an allele that supports telomeres longer than wild type. It is parsimonious to propose that this is attributable to TSA-Telomerase gain-of-functionality compared to wild type. To our knowledge, the only alleles of 
yeast telomerase RNA reported to have elongated telomeres are $\mathrm{TLC} 1+\mathrm{Ku}$ RNAs, which have a second $\mathrm{Ku}$-binding site added at a novel position (Zappulla et al. 2011).

When normalizing for telomerase RNA abundance, telomeres are elongated in TSA-T cells compared with those with wild-type TLC1. This appears to be attributable to stiffening both the Ku and Est1 arms in TSA-T. The "S S -" allele has telomeres 77 bp longer than wild type (Fig. 6C), despite this RNA being only $38 \%$ as abundant (Fig. 6B). This effect appears to be a genetic interaction, since neither the stiffened $\mathrm{Ku}(\mathrm{S}--)$ nor Estl $\left(-\mathrm{S}_{-}\right)$arm alone shows a significant increase. Intriguingly, the $\mathrm{Ku}$ and Est1 arms both function in telomerase recruitment (Stellwagen et al. 2003; Bianchi et al. 2004; Chan et al. 2008; Pfingsten et al. 2012), and it is therefore worth considering how stiffening the Est 1 and $\mathrm{Ku}$ arms relate to this aspect of telomerase holoenzyme mechanism in vivo. In addition, the stiffened $\mathrm{Ku}$ arm may affect telomerase-specific activity. In reconstituted telomerase assays, the stiffened $\mathrm{Ku}$ arm promotes activity in the absence of the Ku protein, implying an effect on telomerase catalytic core formation (Fig. 5B).

Despite the increased telomere extension caused by stiffened $\mathrm{Ku}$ and Est1 arms, TSA-T telomeres are shorter than wild type due to very low telomerase RNA abundance (Fig. 4). We found this to be attributable to stiffening the terminal arm; each allele with the terminal arm stiffened had in vivo abundance ranging from $10 \%$ to $13 \%$ of wild type (Fig. 6B). Correspondingly, each stiffened terminal arm allele supported shortened telomeres as well (Fig. 6C). However, the stiffened-terminal-arm alleles do confer growth to a $t l c 1 \Delta$ strain, with telomeres longer than Mini-T cells (Fig. 6A,C). The reduced telomerase levels and telomere lengths in stiffened terminal arm alleles may indicate that some flexibility is required in the terminal arm for full function. It is possible that $\mathrm{Sm}_{7}$ plays a supporting role in RNP assembly, related to that reported in Schizosaccharomyces pombe telomerase (Tang et al. 2012), and that physical RNA flexibility is important for assisting loading or coordinating Est2 and/or Est3. Alternatively, the low RNA abundance may not be due to stiffening per se, since previously reported truncations in the terminal arm have resulted in similar RNA and telomere phenotypes (Zappulla and Cech 2004). It is possible that stiffening the terminal arm introduces mutations in a previously uncharacterized RNA motif within the stiffened region.

The fact that telomerase is functional in yeast despite stiffened arm "struts" separating the catalytic core from the holoenzyme subunits (Fig. 3) advances our understanding of the structural nature of the yeast telomerase RNP and its mechanism in vivo. When designing TSA-T, we considered several possibilities that could explain the architecture and mechanism represented by the flexible scaffold model (Fig. 7; Zappulla and Cech 2004; Zappulla et al. 2011). First we envisioned that, like many well-studied RNPs, telomerase could form a highly ordered RNA structure

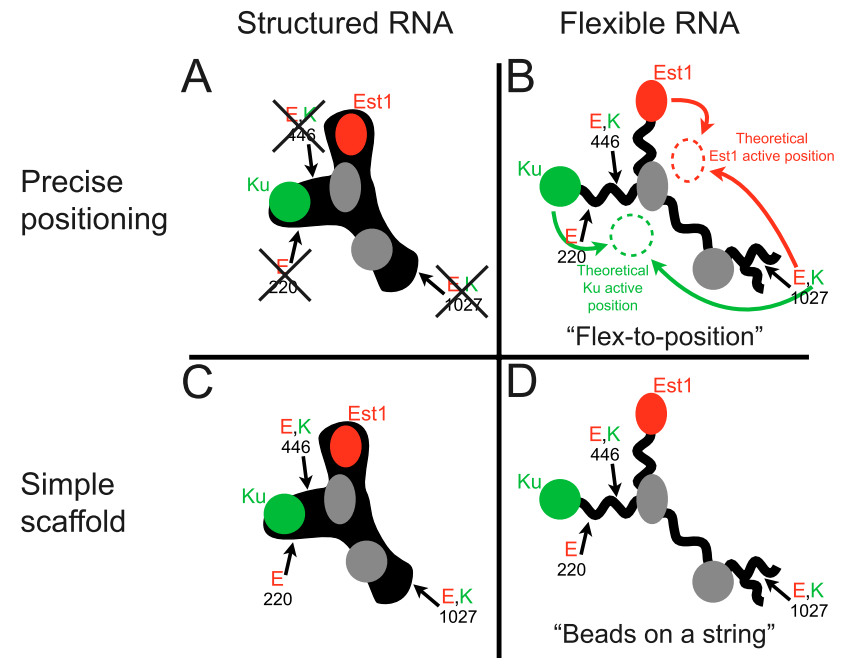

FIGURE 7. Possible models for yeast telomerase RNP holoenzyme architecture and function. (A) Structured telomerase RNP, with Est1 (E; red) and $\mathrm{Ku}(\mathrm{K}$; green) subunits requiring precise positioning by a structured TLC1 RNA (black) for function. Since it has been shown that Est 1 and $\mathrm{Ku}$ can function when repositioned (Zappulla and Cech 2004; Zappulla et al. 2011) (arrows), this model is not favored. (B) Physically flexible telomerase RNA permitting Est1 and Ku subunits to "dock" into hypothetical precise positions (dashed circles) required for function. TLC1 flexibility is indicated by wavy black lines; the arms can bend in three-dimensional space with large accessible volume provided by the wide range of motion. The RNA is a physically flexible tether, allowing Estl and $\mathrm{Ku}$ flex to their active docking positions to function (red and green arrows), even when binding sites on the RNA are repositioned. (C) Telomerase RNA as a structured, simple scaffold. In this model, although precisely positioned in the RNA normally, the protein components do not require specific relative positions to function. Therefore, positional and structural rearrangements are tolerated. $(D)$ Telomerase as a physically flexible scaffold. In this scenario, yeast telomerase RNP architecture and function can be simply summarized as "beads on a string." The RNAbound protein components are tethered and do not need to dock into any precise position within the RNP.

with precise protein subunit positions required for function (Fig. 7A). However, such a model is inconsistent with previously published data supporting a flexible scaffold (Zappulla and Cech 2004; Zappulla et al. 2011), since a highly structured RNP with precise active positions would not tolerate subunit repositioning. On the other hand, a second proposed structural model invokes a requirement for precise positioning of the protein subunits, as long as the RNA is physically flexible (Fig. 7B). In this "flex-to-position" model, the physically flexible arms of TLC1 bend in threedimensional space, allowing the $\mathrm{Ku}$ and Estl subunits to "dock" in their precise functional orientations even when repositioned on the RNA. These "precise positioning" RNA scaffolds stand in contrast to a "simple scaffold" model, in which the protein subunits do not have precise orientations for activity, but rather need only to be held in proximity to each other. In a simple scaffold, TLC1 may be globally structured (Fig. 7C); since the proteins do not need specific positions, the RNA can tolerate binding-site repositioning, 
in accordance with the functionally flexible scaffold model. Alternatively, TLC1 may be relatively unstructured and physically flexible (Fig. 7D); the RNA tethers the proteins together without precise positioning, causing the RNP to behave as "beads on a string."

To test these models, we designed TSA-T with rigid regions, which remove flexibility from the RNP and act as struts to hold the accessory protein subunits away from the core. The fact that TSA-T functions in vivo provides evidence against precise positioning of the proteins within the RNP (Fig. 7A,B); with physical flexibility eradicated from the arms, the proteins would be unable to achieve the necessary active orientations in cis. Instead, functional TSA-T supports a simple scaffold, in which telomerase RNA holds the protein subunits near each other, without precise positioning (Fig. 7C,D).

As to whether wild-type TLC1 is physically rigid (Fig. 7C) or flexible (Fig. 7D) in the RNP in vivo, we favor the latter. Perhaps the strongest evidence favoring this hypothesis is the astonishingly rapid evolution of the arms (Tzfati et al. 2003; Dandjinou et al. 2004; Zappulla and Cech 2004); nucleotides in the non-protein-binding regions of the arms are only $38 \%$ conserved in sequence between Saccharomyces cerevisiae, Saccharomyces paradoxus, Saccharomyces mikatae, and Saccharomyces bayanus, compared with 59\% in the other portions of the RNA (Zappulla and Cech 2004). If a particular structure (or discrete set of structures) existed, there should not be such quasi-unbridled evolutionary change in sequence, nor so few covarying nucleotides. Flexible RNA, on the other hand, can be generated by a vast array of sequences, consistent with the observed rapid evolution in telomerase RNA sequence and length.

In summary, the fact that TSA-T provides function in vivo is additional support for a simple, functionally flexible scaffold model for yeast telomerase RNA (Fig. 7C,D; Zappulla and Cech 2004). The strut-like arms of TSA-T holding essential and important accessory subunits away from the core of the RNP enzyme strongly disfavor a "flexto-position" model for yeast telomerase architecture and mechanism. As to whether wild-type yeast telomerase RNA simple scaffolding is naturally physically flexible or rigid, TSA-T does not necessarily favor one or the other. However, the fact that there are notable phenotypes when arms of TLC1 are stiffened does suggest that there may be somealbeit nonessential—roles for the physical characteristics of telomerase RNA in holoenzyme architecture and function.

\section{MATERIALS AND METHODS}

\section{Creation of telomerase RNAs with dsRNA arms}

We used the secondary structure model of TLC1 (Dandjinou et al. 2004; Zappulla and Cech 2004) as the basis for engineering modified constructs with tracts of purely double-stranded RNA in the arms. Unpaired nucleotides in the three RNA arms present in regions shown to be dispensable for basic function in vivo (Zappulla et al. 2005) were removed from the sequence. For the complete TSA-T sequence, see Supplemental Figure S1B. All unpaired nucleotides in the secondary structure model within the following regions of TLC1 were deleted: nucleotides 27-114 and 815-894 in the terminal arm, nucleotides 132-263 and 334456 for the Ku arm, and nucleotides 507-548 and 661-701 for the Est1 arm (Fig. 1). At the core-proximal ends of the Est1 and terminal arms, the wild-type sequence was modified to create useful restriction enzyme sites to facilitate future modifications; an MluI site was built into the Est1 arm (starting at nucleotide 555 of TSA-T), and a PmeI site was built into the terminal arm (starting at nucleotide 631 of TSA-T). Twenty-two out of 25 uracil residues predicted to be involved in $\mathrm{G} \bullet \mathrm{U}$ pairing in the regions of the arms to be stiffened were converted to $\mathrm{C}$ to promote WatsonCrick base pairing (Fig. 1). A single G•U pair was added at the core-proximal end of each arm to make engineered palindromic restriction enzyme sites unique. Mfold RNA secondary structure predication software was used to model RNA secondary structure (Supplemental Fig. S1). The 1003-nt BglII-NsiI region of the TSA-T gene was synthesized, sequence-verified, and subcloned (GenScript). The BglII-NsiI fragment of TSA-T was then subcloned into plasmid pSD107, which had the BglII-NsiI fragment of TLC1 removed, leaving the upstream and downstream regions of TLC1 intact (pDZ223). To clone the one- and two-stiff-arm TLC1 variants (Figs. 5, 6), restriction enzyme sites near the base of each stiffened arm were used to swap wild-type and stiffened arms between TLC1 in pSD107 and TSA-T in pDZ223. To determine the percentage of nucleotides paired in TLC1, TSA-T, and Mini-T referred to in the Results, all nucleotides involved in base pairing were counted, and divided by the total nucleotide length of the RNA: 711 paired/1157 total for TLC1, 685/956 for TSA-T, and 291/500 for Mini-T. For the percentage of each arm stiffened in TSA-T, the number of nucleotides in the regions of the arms of TLC1 that were converted to dsRNA in TSA-T was divided by the total nucleotides in each arm: 290 in stiffened region/325 total in the Ku arm (89\%), 121/201 in the Est1 arm (60\%), and 190/479 in the whole terminal arm (40\%).

\section{Experiments in yeast}

To test stiffened arm TLC1 function in vivo for Figures 3 and 6, TRP1-marked centromeric (CEN) plasmids expressing the desired genes were transformed into strain TCy43 (MAT-a ura3-53

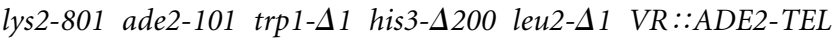
adh4::URA3-TEL tlc1s::LEU2 rad52A::HIS3 pTLC1-LYS2-CEN) (Seto et al. 1999). After shuffling out TLC1 (LYS2/CEN) on solid medium containing $\alpha$-aminoadipate, colonies were restreaked 10 times on synthetic compete media plates lacking tryptophan, with each restreak representing about 25 generations of yeast growth. For the increased expression of TSA-T for Figure 4, the TSA-T gene, including 518 bp upstream of and 895 bp downstream from the native TLC1 gene, were cloned into the $2 \mu$ expression vector pRS324. To add a second copy of TLC1 to pSD107, the gene, including the 518-bp upstream and 895-bp downstream regions, was cloned into EcoRI- and XhoI-digested pSD107, resulting in a version of the vector harboring two complete TLC1 genes in tandem. A two-copy TSA-T in pDZ223 was made by the same procedure. The plasmids for Figure 4 were transformed into strain yVL1009 (MAT- $\alpha$ tlc1 ::LEU2 rad52::LYS 



URA3-CEN) (Chappell and Lundblad 2004), which is capable of maintaining $2 \mu$ vectors. From this strain the plasmid shuffle was performed on 5-fluoroorotic acid (5-FOA), and cells were restreaked 10 times on complete synthetic medium lacking tryptophan.

\section{Southern blots}

Southern blots were performed as previously described (Zappulla et al. 2005, 2011). Briefly, cell pellets for genomic DNA isolation were prepared from cultures made from serially restreaked plates, with each streak representing about 25 generations. Genomic DNA was isolated (Gentra Puregene system), and equal amounts were digested with XhoI and electrophoresed through a $1.1 \%$ agarose gel at $70 \mathrm{~V}$ for $17 \mathrm{~h}$, and transferred to Hybond-N+ Nylon membrane (GE). The blot was then probed for telomeric sequences and a 1627-bp nontelomeric fragment of chromosome IV. Average $\mathrm{Y}^{\prime}$ telomere fragment length was quantified using the weighted average mobility (WAM) method described previously (Zappulla et al. 2011). To calculate the average length in base pairs of the $\mathrm{Y}^{\prime}$ telomeres, the average nontelomeric sequence length of $\mathrm{Y}^{\prime}$ fragments was subtracted from the experimentally determined weighted average motility of the $\mathrm{Y}^{\prime}$ telomere signal. This length, $1096 \mathrm{bp}$, was derived by finding the distance, in base pairs, of the nearest XhoI site to the start of the telomeric sequence in each $\mathrm{Y}^{\prime}$ telomere in the Saccharomyces Genome Database.

\section{Total RNA dot blots}

Total cellular RNA was extracted from late-log-phase or earlystationary-phase yeast cultures by a slightly modified version of the hot phenol RNA isolation method (Kohrer and Domdey 1991). After boiling, $2.5 \mu \mathrm{g}$ of RNA was spotted six times onto Hybond-N+ Nylon Membrane (GE) to provide three technical replicates of each biological replicate (a single technical replicated dot for each biological sample for each probe is shown in Figs. 3, 4, and 6). The membrane was cut in half such that three dots of each sample were on each membrane section, air-dried, UV-crosslinked (SpectroLinker XL-1500 UV Crosslinker, "Optimal crosslink" setting), and pre-hybridized in Church buffer for $10 \mathrm{~min}$ at $55^{\circ} \mathrm{C}$. One membrane was probed for the $3^{\prime}$ region of TLC1 shared by TLC1 and TSA-T (nucleotides 906-1140 in TLC1), while the other was probed for the U1 snRNA (Friedman and Cech 1999). The three dots for each sample (i.e., the technical replicates for each biological sample) were averaged for both probes, and telomerase RNA levels were normalized to U1 levels.

\section{RNase protection assay}

TLC1, TSA-T, and Mini-T RNAs were transcribed in vitro using T7 RNA polymerase in the presence of $\left[\alpha-{ }^{32} \mathrm{P}\right] \mathrm{GTP}$. To accomplish this, $2 \mu \mathrm{g}$ of FokI-linearized plasmid containing a T7 promoter was used as template for $\mathrm{T} 7$ polymerase in a reaction containing $10 \mathrm{mM}$ DTT, $40 \mathrm{mM}$ Tris $7.5,12 \mathrm{mM} \mathrm{MgCl}_{2}, 2 \mathrm{mM}$ spermidine, yeast inorganic pyrophosphatase (0.4 units; NEB), $25 \mathrm{mM}$ rNTPs, and $\left[\alpha-{ }^{32} \mathrm{P}\right] \mathrm{GTP}(100 \mu \mathrm{Ci})$, and incubated for $1 \mathrm{~h}$ at $37^{\circ} \mathrm{C}$. All $30 \mu \mathrm{L}$ of reaction products was treated with DNase I (2 units; NEB) for $30 \mathrm{~min}$, phenol:chloroform extracted, ethanolprecipitated, and resuspended in $24 \mu \mathrm{L}$ of $0.5 \times \mathrm{TE}$. Twelve microliters of RNA was then refolded by heating for $2 \mathrm{~min}$ to $95^{\circ} \mathrm{C}$, then cooling for $2 \mathrm{~min}$ on ice. The RNA solution was brought to a volume of $18 \mu \mathrm{L}$ with a final concentration of $111 \mathrm{mM}$ HEPES (pH 8), $111 \mathrm{mM} \mathrm{NaCl}$, and $6.7 \mu \mathrm{M} \mathrm{MgCl}_{2}$, and incubated for $20 \mathrm{~min}$ at room temperature. Next, the RNA was digested with RNase A $(0.3 \mu \mathrm{g} / \mu \mathrm{L})$ and RNase T1 (6 units; Fermentas) in $400 \mu \mathrm{L}$ of RNase digestion buffer (10 mM Tris-Cl at $\mathrm{pH} 7.5$, $300 \mathrm{mM} \mathrm{NaCl}, 5 \mathrm{mM}$ EDTA) and incubated for $45 \mathrm{~min}$ at room temperature (Gilman 2001). RNase digestion was stopped by adding $10 \mu \mathrm{L}$ of $20 \%$ SDS and $2.5 \mu \mathrm{L}$ of Proteinase K, incubating for $15 \mathrm{~min}$ at $37^{\circ} \mathrm{C}$, phenol:chloroform extracting, and ethanol precipitating (Gilman 2001). The RNA products were then electrophoresed through a $10 \%$ polyacrylamide/TBE/urea sequencing gel at $90 \mathrm{~W}$ for $75 \mathrm{~min}$. The gel was dried and exposed on a storage phosphor screen, and imaged on a Typhoon 9410 Variable Mode Imager.

\section{Reconstituted telomerase activity assays}

Linearized "run off" DNA templates for T7 transcription of telomerase RNAs were made for Figure 2 using FokI-digested plasmids. For Figure 4, PCR products of the gene were transcribed using a T7 promoter included at the $5^{\prime}$ end of the forward primer. In vitro telomerase activity assays were performed as described previously (Zappulla et al. 2005). Briefly, linear DNA template for telomerase RNA was mixed with plasmid containing T7-ProAEst2 in an RRL transcription and translation system. Telomerase was immunopurified with IgG-Sephadex beads. Telomerase beads were then incubated with telomeric primer, dNTPs, and $\left[\alpha_{-}{ }^{32}\right.$ P]dTTP. Products were electrophoresed through a $10 \%$ polyacrylamide/TBE/urea gel, and imaged using phosphor screens and a Typhoon 9410 Variable Mode Imager. As an internal control for product recovery and loading, $\sim 1 \mathrm{nM}\left[\gamma^{-}{ }^{32} \mathrm{P}\right]$-labeled primer was added before the telomerase reaction. Activity levels were normalized to the internal control, and to ProA-Est2 levels. $\left[{ }^{35} \mathrm{~S}\right]$-Met-labeled ProA-Est 2 levels were determined by electrophoresing $2.5 \mu \mathrm{L}$ of bead-bound telomerase in a $7.5 \%$ SDSpolyacrylamide gel, and phosphorimaging.

\section{SUPPLEMENTAL MATERIAL}

Supplemental material is available for this article.

\section{ACKNOWLEDGMENTS}

We thank members of the Zappulla laboratory and Tom Cech for comments on the manuscript. This work was supported by US National Institutes of Health funding from R00 GM80400 to D.C.Z. as well as startup funds from The Johns Hopkins University. K.J.L. is supported by National Institutes of Health Cellular and Molecular Biology graduate student training grant 2T32 GM007231.

Received April 14, 2012; accepted June 5, 2012.

\section{REFERENCES}

Abels JA, Moreno-Herrero F, van der Heijden T, Dekker C, Dekker NH. 2005. Single-molecule measurements of the persistence length of double-stranded RNA. Biophys J 88: 2737-2744. 
Autexier C, Greider CW. 1994. Functional reconstitution of wild-type and mutant Tetrahymena telomerase. Genes Dev 8: 563-575.

Ban N, Nissen P, Hansen J, Moore PB, Steitz TA. 2000. The complete atomic structure of the large ribosomal subunit at $2.4 \AA$ resolution. Science 289: 905-920.

Berman AJ, Akiyama BM, Stone MD, Cech TR. 2011. The RNA accordion model for template positioning by telomerase RNA during telomeric DNA synthesis. Nat Struct Mol Biol 18: 13711375.

Bertuch AA, Lundblad V. 2003. The Ku heterodimer performs separable activities at double-strand breaks and chromosome termini. Mol Cell Biol 23: 8202-8215.

Bhattacharyya A, Lilley DM. 1989. The contrasting structures of mismatched DNA sequences containing looped-out bases (bulges) and multiple mismatches (bubbles). Nucleic Acids Res 17: 68216840.

Bianchi A, Negrini S, Shore D. 2004. Delivery of yeast telomerase to a DNA break depends on the recruitment functions of $\mathrm{Cdc13}$ and Est1. Mol Cell 16: 139-146.

Blackburn EH. 2006. A history of telomere biology. In Telomeres (ed. T de Lange et al.), pp. 1-19. Cold Spring Harbor Laboratory Press, Cold Spring Harbor, NY.

Blackburn EH, Collins K. 2011. Telomerase: An RNP enzyme synthesizes DNA. Cold Spring Harb Perspect Biol 3: a003558. doi: 10.1101/cshperspect.a003558.

Bryan TM, Goodrich KJ, Cech TR. 2000. Telomerase RNA bound by protein motifs specific to telomerase reverse transcriptase. Mol Cell 6: 493-499.

Bustamante C, Smith SB, Liphardt J, Smith D. 2000. Single-molecule studies of DNA mechanics. Curr Opin Struct Biol 10: 279-285.

Cech TR. 2004. Beginning to understand the end of the chromosome. Cell 116: 273-279.

Chan A, Boule JB, Zakian VA. 2008. Two pathways recruit telomerase to Saccharomyces cerevisiae telomeres. PLoS Genet 4: e1000236. doi: 10.1371/journal.pgen.1000236.

Chanfreau G, Buckle M, Jacquier A. 2000. Recognition of a conserved class of RNA tetraloops by Saccharomyces cerevisiae RNase III. Proc Natl Acad Sci 97: 3142-3147.

Chappell AS, Lundblad V. 2004. Structural elements required for association of the Saccharomyces cerevisiae telomerase RNA with the Est2 reverse transcriptase. Mol Cell Biol 24: 7720-7736.

Chen JL, Greider CW. 2003. Template boundary definition in mammalian telomerase. Genes Dev 17: 2747-2752.

Cloutier TE, Widom J. 2004. Spontaneous sharp bending of doublestranded DNA. Mol Cell 14: 355-362.

Dandjinou AT, Levesque N, Larose S, Lucier JF, Abou Elela S, Wellinger RJ. 2004. A phylogenetically based secondary structure for the yeast telomerase RNA. Curr Biol 14: 1148-1158.

Feng J, Funk WD, Wang SS, Weinrich SL, Avilion AA, Chiu CP, Adams RR, Chang E, Allsopp RC, Yu J, et al. 1995. The RNA component of human telomerase. Science 269: 1236-1241.

Friedman KL, Cech TR. 1999. Essential functions of amino-terminal domains in the yeast telomerase catalytic subunit revealed by selection for viable mutants. Genes Dev 13: 2863-2874.

Fulle S, Gohlke H. 2009. Constraint counting on RNA structures: Linking flexibility and function. Methods 49: 181-188.

Gillis AJ, Schuller AP, Skordalakes E. 2008. Structure of the Tribolium castaneum telomerase catalytic subunit TERT. Nature 455: 633637.

Gilman M. 2001. Ribonuclease Protection Assay. Curr Protoc Mol Biol 24: 4.7.1-4.7.8.

Gravel S, Larrivee M, Labrecque P, Wellinger RJ. 1998. Yeast Ku as a regulator of chromosomal DNA end structure. Science 280: 741744.

Greider CW, Blackburn EH. 1989. A telomeric sequence in the RNA of Tetrahymena telomerase required for telomere repeat synthesis. Nature 337: 331-337.

Guttman M, Donaghey J, Carey BW, Garber M, Grenier JK, Munson G, Young G, Lucas AB, Ach R, Bruhn L, et al. 2011. lincRNAs act in the circuitry controlling pluripotency and differentiation. Nature 477: 295-300.

Hagerman PJ. 1988. Flexibility of DNA. Annu Rev Biophys Biophys Chem 17: 265-286.

Hagerman PJ. 1997. Flexibility of RNA. Annu Rev Biophys Biomol Struct 26: 139-156.

Hughes TR, Evans SK, Weilbaecher RG, Lundblad V. 2000. The Est3 protein is a subunit of yeast telomerase. Curr Biol 10: 809-812.

Jang SB, Hung LW, Chi YI, Holbrook EL, Carter RJ, Holbrook SR. 1998. Structure of an RNA internal loop consisting of tandem C-A ${ }^{+}$base pairs. Biochemistry 37: 11726-11731.

Kachouri-Lafond R, Dujon B, Gilson E, Westhof E, Fairhead C, Teixeira MT. 2009. Large telomerase RNA, telomere length heterogeneity and escape from senescence in Candida glabrata. FEBS Lett 583: 3605-3610.

Kohrer K, Domdey H. 1991. Preparation of high molecular weight RNA. Methods Enzymol 194: 398-405.

Lai CK, Miller MC, Collins K. 2002. Template boundary definition in Tetrahymena telomerase. Genes Dev 16: 415-420.

Lai CK, Miller MC, Collins K. 2003. Roles for RNA in telomerase nucleotide and repeat addition processivity. Mol Cell 11: 16731683.

Le S, Moore JK, Haber JE, Greider CW. 1999. RAD50 and RAD51 define two pathways that collaborate to maintain telomeres in the absence of telomerase. Genetics 152: 143-152.

Lendvay TS, Morris DK, Sah J, Balasubramanian B, Lundblad V. 1996. Senescence mutants of Saccharomyces cerevisiae with a defect in telomere replication identify three additional EST genes. Genetics 144: 1399-1412.

Leung AK, Nagai K, Li J. 2011. Structure of the spliceosomal U4 snRNP core domain and its implication for snRNP biogenesis. Nature 473: 536-539.

Li B, Lustig AJ. 1996. A novel mechanism for telomere size control in Saccharomyces cerevisiae. Genes Dev 10: 1310-1326.

Lin J, Ly H, Hussain A, Abraham M, Pearl S, Tzfati Y, Parslow TG, Blackburn EH. 2004. A universal telomerase RNA core structure includes structured motifs required for binding the telomerase reverse transcriptase protein. Proc Natl Acad Sci 101: 1471314718.

Livengood AJ, Zaug AJ, Cech TR. 2002. Essential regions of Saccharomyces cerevisiae telomerase RNA: Separate elements for Estlp and Est2p interaction. Mol Cell Biol 22: 2366-2374.

Lundblad V, Blackburn EH. 1993. An alternative pathway for yeast telomere maintenance rescues est $1^{-}$senescence. Cell 73: 347-360.

Lundblad V, Szostak JW. 1989. A mutant with a defect in telomere elongation leads to senescence in yeast. Cell 57: 633-643.

Mastroianni AJ, Sivak DA, Geissler PL, Alivisatos AP. 2009. Probing the conformational distributions of subpersistence length DNA. Biophys J 97: 1408-1417.

McEachern MJ, Blackburn EH. 1996. Cap-prevented recombination between terminal telomeric repeat arrays (telomere CPR) maintains telomeres in Kluyveromyces lactis lacking telomerase. Genes Dev 10: $1822-1834$.

Moore PB, Steitz TA. 2002. The involvement of RNA in ribosome function. Nature 418: 229-235.

Nakayashiki H, Kadotani N, Mayama S. 2006. Evolution and diversification of RNA silencing proteins in fungi. $J$ Mol Evol 63: 127-135.

Peterson SE, Stellwagen AE, Diede SJ, Singer MS, Haimberger ZW, Johnson CO, Tzoneva M, Gottschling DE. 2001. The function of a stem-loop in telomerase RNA is linked to the DNA repair protein Ku. Nat Genet 27: 64-67.

Pfingsten JS, Goodrich KJ, Taabazuing C, Ouenzar F, Chartrand P, Cech TR. 2012. Mutually exclusive binding of telomerase RNA and DNA by Ku alters telomerase recruitment model. Cell 148: 922 932.

Prescott J, Blackburn EH. 1997. Telomerase RNA mutations in Saccharomyces cerevisiae alter telomerase action and reveal nonprocessivity in vivo and in vitro. Genes Dev 11: $528-540$. 
Qiao F, Cech TR. 2008. Triple-helix structure in telomerase RNA contributes to catalysis. Nat Struct Mol Biol 15: 634-640.

Richards RJ, Wu H, Trantirek L, O'Connor CM, Collins K, Feigon J. 2006. Structural study of elements of Tetrahymena telomerase RNA stem-loop IV domain important for function. RNA 12: 1475-1485.

Robart AR, O'Connor CM, Collins K. 2010. Ciliate telomerase RNA loop IV nucleotides promote hierarchical RNP assembly and holoenzyme stability. RNA 16: 563-571.

Sandell LL, Zakian VA. 1993. Loss of a yeast telomere: Arrest, recovery, and chromosome loss. Cell 75: 729-739.

Seto AG, Zaug AJ, Sobel SG, Wolin SL, Cech TR. 1999. Saccharomyces cerevisiae telomerase is an Sm small nuclear ribonucleoprotein particle. Nature 401: 177-180.

Seto AG, Livengood AJ, Tzfati Y, Blackburn EH, Cech TR. 2002. A bulged stem tethers Estlp to telomerase RNA in budding yeast. Genes Dev 16: 2800-2812.

Seto AG, Umansky K, Tzfati Y, Zaug AJ, Blackburn EH, Cech TR. 2003. A template-proximal RNA paired element contributes to Saccharomyces cerevisiae telomerase activity. RNA 9: 1323-1332.

Shippen-Lentz D, Blackburn EH. 1990. Functional evidence for an RNA template in telomerase. Science 247: 546-552.

Singer MS, Gottschling DE. 1994. TLC1: Template RNA component of Saccharomyces cerevisiae telomerase. Science 266: 404-409.

Stellwagen AE, Haimberger ZW, Veatch JR, Gottschling DE. 2003. Ku interacts with telomerase RNA to promote telomere addition at native and broken chromosome ends. Genes Dev 17: 2384-2395.

Stone MD, Mihalusova M, O'Connor CM, Prathapam R, Collins K, Zhuang X. 2007. Stepwise protein-mediated RNA folding directs assembly of telomerase ribonucleoprotein. Nature 446: 458-461.

Talley JM, DeZwaan DC, Maness LD, Freeman BC, Friedman KL. 2011. Stimulation of yeast telomerase activity by the ever shorter telomere 3 (Est3) subunit is dependent on direct interaction with the catalytic protein Est2. J Biol Chem 286: 26431-26439.

Tang W, Kannan R, Blanchette M, Baumann P. 2012. Telomerase RNA biogenesis involves sequential binding by $\mathrm{Sm}$ and Lsm complexes. Nature 484: 260-264.

Tzfati Y, Fulton TB, Roy J, Blackburn EH. 2000. Template boundary in a yeast telomerase specified by RNA structure. Science 288: 863867.

Tzfati Y, Knight Z, Roy J, Blackburn EH. 2003. A novel pseudoknot element is essential for the action of a yeast telomerase. Genes Dev 17: 1779-1788.
Verschoor A, Warner JR, Srivastava S, Grassucci RA, Frank J. 1998. Three-dimensional structure of the yeast ribosome. Nucleic Acids Res 26: 655-661.

Virta-Pearlman V, Morris DK, Lundblad V. 1996. Est1 has the properties of a single-stranded telomere end-binding protein. Genes Dev 10: 3094-3104.

Walker JR, Corpina RA, Goldberg J. 2001. Structure of the Ku heterodimer bound to DNA and its implications for double-strand break repair. Nature 412: 607-614.

Wang KC, Chang HY. 2011. Molecular mechanisms of long noncoding RNAs. Mol Cell 43: 904-914.

Weinrich SL, Pruzan R, Ma L, Ouellette M, Tesmer VM, Holt SE, Bodnar AG, Lichtsteiner S, Kim NW, Trager JB, et al. 1997. Reconstitution of human telomerase with the template RNA component hTR and the catalytic protein subunit hTRT. Nat Genet 17: 498-502.

Wiggins PA, Nelson PC. 2006. Generalized theory of semiflexible polymers. Phys Rev E Stat Nonlin Soft Matter Phys 73: 031906. doi: 10.1103/PhysRevE.73.031906.

Wiggins PA, van der Heijden T, Moreno-Herrero F, Spakowitz A, Phillips R, Widom J, Dekker C, Nelson PC. 2006. High flexibility of DNA on short length scales probed by atomic force microscopy. Nat Nanotechnol 1: 137-141.

Zacharias M, Hagerman PJ. 1996. The influence of symmetric internal loops on the flexibility of RNA. J Mol Biol 257: 276-289.

Zappulla DC, Cech TR. 2004. Yeast telomerase RNA: A flexible scaffold for protein subunits. Proc Natl Acad Sci 101: 10024-10029.

Zappulla DC, Cech TR. 2006. RNA as a flexible scaffold for proteins: Yeast telomerase and beyond. Cold Spring Harb Symp Quant Biol 71: 217-224.

Zappulla DC, Goodrich K, Cech TR. 2005. A miniature yeast telomerase RNA functions in vivo and reconstitutes activity in vitro. Nat Struct Mol Biol 12: 1072-1077.

Zappulla DC, Goodrich KJ, Arthur JR, Gurski LA, Denham EM, Stellwagen AE, Cech TR. 2011. Ku can contribute to telomere lengthening in yeast at multiple positions in the telomerase RNP. RNA 17: 298-311.

Zaug AJ, Linger J, Cech TR. 1996. Method for determining RNA 3' ends and application to human telomerase RNA. Nucleic Acids Res 24: 532-533.

Zhou J, Hidaka K, Futcher B. 2000. The Est1 subunit of yeast telomerase binds the Tlcl telomerase RNA. Mol Cell Biol 20: 1947-1955. 

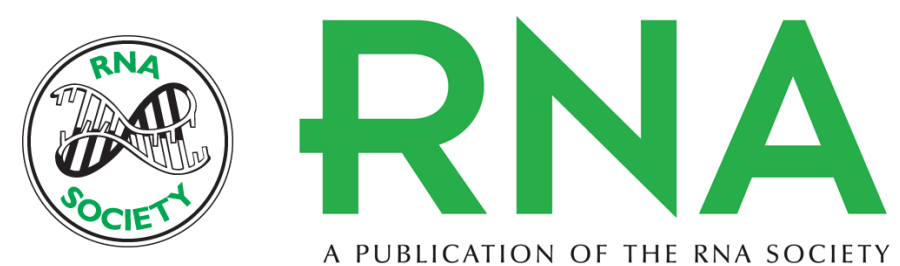

A PUBLICATION OF THE RNA SOCIETY

\section{Stiffened yeast telomerase RNA supports RNP function in vitro and in vivo}

Kevin J. Lebo and David C. Zappulla

RNA 2012 18: 1666-1678 originally published online July 31, 2012

Access the most recent version at doi:10.1261/rna.033555.112

\section{Supplemental http://rnajournal.cshlp.org/content/suppl/2012/07/17/rna.033555.112.DC1 Material}

References This article cites 77 articles, 31 of which can be accessed free at: http://rnajournal.cshlp.org/content/18/9/1666.full.html\#ref-list-1

\section{License}

Email Alerting Receive free email alerts when new articles cite this article - sign up in the box at the Service top right corner of the article or click here. 